\title{
Comparison of Pain and Requirement of Injectable Anti-Inflammatory Drugs with and without Port Site Infiltration of Injection Bupivacaine in Laparoscopic Surgeries
}

\author{
Fakhar Hameed ${ }^{1}$, Kashif Liaqat ${ }^{2}$, Muhammad Saleem Iqbal $^{3}$, Hasnain Ejaz ${ }^{4}$, Muhammad Khalid ${ }^{5}$, Iqra Shahzadi ${ }^{6}$, \\ Urooj Habib $^{7}$, Waseem Shahzad ${ }^{8}$
}

1 Professor of Surgery, Faisalabad Medical University, Faisalabad Pakistan

1 Principal author, Manuscript writing, Overall supervision

2 Senior Registrar, Department of Surgery, DHQ Hospital, Faisalabad Pakistan

2 Review of literature, Correction of references

3 Assistant Professor, Department of Surgery, Faisalabad Medical University, Faisalabad Pakistan

Proof reading of manuscript

4 Senior Registrar, Department of Surgery, DHQ Hospital, Faisalabad Pakistan

4 Literature review, Compilation of results

5 Post Graduate Resident, Department of Surgery, DHQ Hospital, Faisalabad Pakistan Collection of data

6 Post Graduate Resident, Department of Surgery, DHQ Hospital, Faisalabad Pakistan

6 Collection of data

7 Post Graduate Resident, Department of Surgery, DHQ Hospital, Faisalabad Pakistan

Collection of data

Post Graduate Resident, Department of Surgery, DHQ Hospital, Faisalabad Pakistan

Collection of data

Submitted for Publication: 16-10-2020
Accepted for Publication 07-12-2020
CORRESPONDING AUTHOR
Dr. Fakhar Hameed
Associate Professor, Department of Surgery,
Faisalabad Medical University / DHQ Hospital,
Faisalabad Pakistan
Email: fakharhameed@hotmail.com

ABSTRACT

Background: Laparoscopic surgery is associated with shorter hospital stay, less post-operative pain and excellent cosmesis. Post-operative pain is lesser in laparoscopic procedures but in some cases, it is not absolutely painless. The aim of different methods to reduce the post-operative pain is to avoid the use of opioids by using anti-inflammatory drugs and infiltration of local anesthesia either intra-peritoneal or in the wound. Theoretically peripheral blockage of pain stimuli with local anesthetic agent is more effective than treating pain. For this purpose, Bupivacaine has been recently used to be injected at port sites. Objective: To evaluate the pain and requirement of injectable anti-inflammatory drug (inj. Ketorolac 30mg) after port site infiltration of inj. bupivacaine in laparoscopic cases. Study Design: Prospective randomized study of elective laparoscopic procedures. Settings: Surgical Unit-IV, DHQ Teaching Hospital Faisalabad, Medical University Faisalabad Pakistan. Duration: November 2015 to May 2017. Methodology: Two hundred and sixty patients included in the study were divided into two groups with equal number in each group. Results: In the study group(A), 103(79.3\%) patients were females of 27(20.7\%) patients were males. All female patients in the study group underwent LC and among males, 26(96.3\%) patients underwent TAPP and 1(3.7\%) patient underwent LC. In the control group(B) $97(74.6 \%)$ patients were females, $33(25.4 \%)$ patients were male. All female patients (100\%) underwent LC and among the males, 30 patients $(90.9 \%)$ underwent TAPP, 3(9.1\%) patients underwent LC. In the study group, the mean VAS in the study group at 2 hours, 6 hours, 12 hours after surgery was 1.6, 1.7, 1.6 with standard deviation 1.6, 1.7, 1.8 respectively while in the control group VAS was 2.9, 3.1, 2.6 with standard deviation 2.1, 1.8, 1.9 respectively. In the study group the mean of anti-inflammatory drug injections (Ketorolac) needed was 1.0000 with standard deviation 0.7 and in control group, the same was 1.3 with standard deviation 70.8. The previous was less than 0.05. Conclusion: Infiltration of local anesthetic agent i.e., Bupivacaine results in almost total painless procedure in laparoscopic surgery, the timing and anatomical site of injection should be investigated further.

Keywords: Pain, Anti-Inflammatory Drugs, Port-site, Bupivacaine.

How to Cite: Hameed F, Liaqat K, Iqbal MS, Ejaz H, Khalid M, Shahzadi I, Habib U, Shahzad W. Evaluation of Pain and Requirement of Injectable AntiInflammatory Drugs after Port Site Infiltration of Injection Bupivacaine in Laparoscopic Cases. APMC 2020;14(4):340-4. DOI: 10.29054/ APMC/2020.1060

\section{INTRODUCTION}

For a long time, only the gynecologists had been using laparoscopy to diagnose the pelvic pathologies and to perform minor surgeries like tubal ligation. When Phylip Mouret in 1987 and in 1988 Francois Dubios and Jacques
Parisant performed successful laparoscopic cholecystectomies, only then the value of laparoscopy was recognized by the general surgeons. ${ }^{1}$

Later on, because of this procedure being associated with lesser post-operative pain plus patient discomfort, 
shorter stay at hospital and excellent cosmesis, it has been adopted and accepted all over the world warmly and has resulted in revolution in the management of cholelithiasis, and now many other surgical procedures are also being performed laparoscopically. ${ }^{2}$

If compared with open procedures, Post-operative pain is lesser in laparoscopic procedures, but in some cases, it is not painless and is still an issue. The proposed mechanism of pain is that it is multifactorial in nature and severity and varies among individuals and aims of different methods to treat the post-operative pain are to avoid the use of opioids, by the use of anti-inflammatory drugs and infiltration of local anesthesia either intraperitoneal or in the wounds. ${ }^{3}$

Post-operative pain is the main cause of delayed mobility and extended hospital stay of patients. Therefore, surgeons are very keen to minimize the post-operative pain. ${ }^{4}$

Post-operatively, anti-inflammatory drugs or opioids are mostly used for pain relief, but they have many side effects and many a times are not fully affective. Many surgeons have been practicing injection of local anesthetic agent at port sites to combat the post-operative pain, after laparoscopic procedures. It is advantageous because it is easy to inject, is safe and cost effective. ${ }^{5}$ Theoretically, speaking, peripheral blockage of pain stimuli with local anesthetic agent is more effective than treating the pain. For this purpose, bupivacaine has been recently used and is injected at port sites. ${ }^{6}$

The purpose of this study was to evaluate the pain and requirement of injectable anti-inflammatory drug (inj. Ketorolac 30mg) after port site infiltration of injection bupivacaine in laparoscopic cases.

\section{METHODOLOGY}

Study Design: Prospective randomized study of elective laparoscopic procedures.

Settings: Surgical Unit 4, DHQ hospital, Faisalabad, Faisalabad Medical University, Faisalabad.

Duration: November 2015 to May 2017.

Sample Technique: Non-probability consecutive sampling.

Sample Size: 260 patients ,130 in each group.

Inclusion Criteria: All the patients with clinical diagnosis of symptomatic gallstones and inguinal hernia above the age of 18 years.

Exclusion Criteria: Patients with gangrenous gall bladder or empyema gall bladder, patients with strangulated hernias, Patients younger than 18 years, patients with previous open pelvic surgery and patients not fit for general anesthesia were excluded from the study.

Data Collection: Informed consent was taken from all the patients, who were included in the study for the study and type of surgery. Same consultant surgeon performed all the surgeries under general anesthesia. After obtaining informed consent from the patients, demographic details of the patient like name, age, sex, occupation and address were noted on a specific proforma. Patients were randomly allocated into two groups, study group and control group, based on computer generated table of random numbers. History and complete physical examination of the patient was done by a Senior Registrar.

Laparoscopic cholecystectomy was done by standard 4ports method. For inguinal hernias, all the procedures were standard TAPP. After the completion of the procedure, in study group, 6cc of Inj. Bupivacaine $(5 \mathrm{mg} / \mathrm{ml})$ was injected in all $10 \mathrm{~mm}$ ports and $4 \mathrm{cc}$ in all $5 \mathrm{~mm}$ ports and no injections given in control groups. Post-operatively, same IV anti-inflammatory drug was given to all the patients as per their need. The pain score was recorded on a visual analog score (VAS) index at an interval of 2 hours, 6 hours and 12 hours after the surgery, between 0 to 10, according to the severity of pain. Number of anti-inflammatory drug (Ketorolac 30mg) injections required by each patient was also recoded. All the information was recorded on proforma.

Data Analysis: The data was analyzed by statistical program of social sciences version 20. Descriptive statistics were used to summarize the data. Mean and standard deviation were calculated for quantitative data like age, VAS, number of anti-inflammatory injections given in first 12 hours after the surgery. Frequency and percentage were calculated for qualitative data like, gender. Independent sample t-test was used to compare the VAS and number of anti-inflammatory drug injection given. p-value of less than 0.05 was considered significant.

\section{RESULTS}

260 patients were included in the study. 130 patients were there in each group. In the study group(A), 103 (79.2\%) patients were females and $27(20.7 \%)$ patients were male. Among the females, all the patients (100\%) underwent LC and among the males, $26(96.3 \%)$ patients underwent TAPP and $1(3.7 \%)$ patient underwent LC. Minimum age in study group was 18 years and maximum age was 85 years with mean age of 39.57 with Std. Deviation 10.4. In the control group, $97(74.6 \%)$ patients were females and $33(25.4 \%)$ patients were male. Among the females, all the patients $(100 \%)$ underwent LC and among the males, 30 patients $(90.9 \%)$ underwent TAPP and $3(9.1 \%)$ patients underwent LC. Minimum age in control group was 18 years and maximum age was 65 years with mean age of 37.3 and Std. Deviation 9.8. In the study group the mean VAC at 2 hours, 6 hours and 12 hours after the surgery was 1.6, 1.7 and 1.6 with Std. Deviations 1.6, 1.7 and 1.8 respectively while in control group the VAS was 2.9, 3.1 and 2.6 with Std. Deviations 2.1, 1.8 and 1.9 respectively. In study group, the total number of injections (Ketorolac) required by all the patients were 132 with an average of 1.01 and in control group, the same were 312 with an 
average of 2.4. In the study group, the mean of antiinflammatory drug injections needed was 1.0000 with std. Deviation of 0.7 and in control group; the same was 1.3 with Std. Deviation of .88235 . The p-value was less than 0.05 .

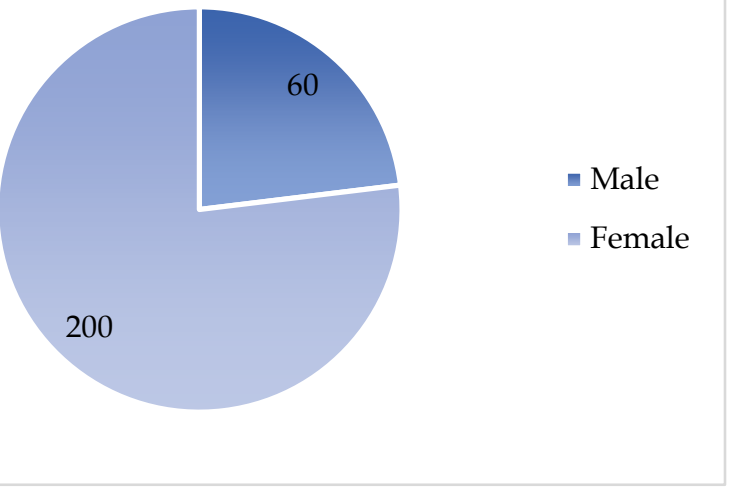

Figure 1: Gender distribution

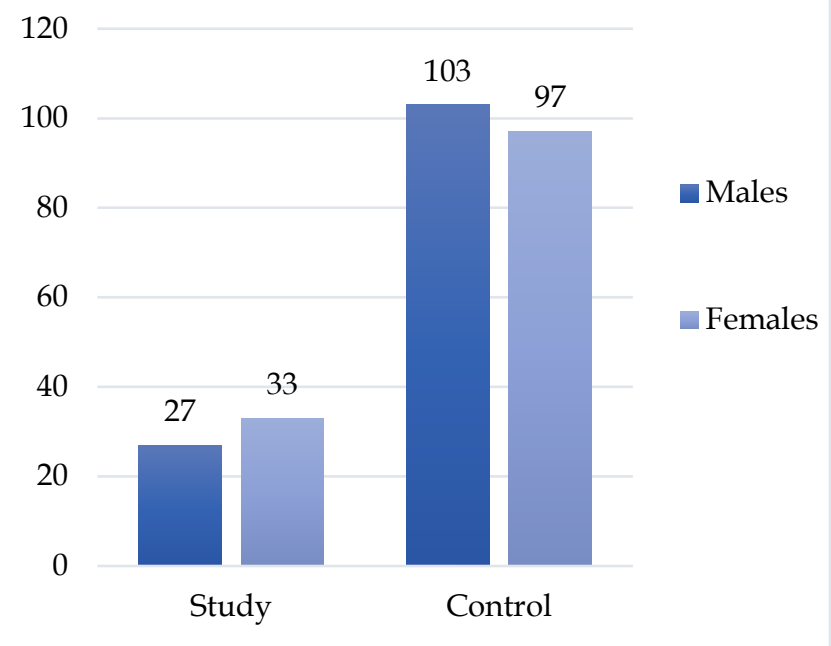

Figure 2: Gender distribution in both groups

Table 1: Demographic details

\begin{tabular}{|c|c|c|c|c|}
\hline & $\begin{array}{c}\text { Study group of } \\
\text { patients }\end{array}$ & $\mathbf{N}$ & Mean & $\begin{array}{c}\text { Std. } \\
\text { Deviation }\end{array}$ \\
\hline \multirow{2}{*}{ Age } & Group A & 130 & 39.6 & 10.4 \\
\cline { 2 - 5 } & Group B & 130 & 37.3 & 9.8 \\
\hline
\end{tabular}

Table 2: Gender percentage in groups

\begin{tabular}{|c|c|c|c|}
\hline \multirow{2}{*}{ Gender } & \multicolumn{2}{|c|}{ Group } & \multirow{2}{*}{ Total } \\
\cline { 2 - 3 } & Study Group & Control Group & \\
\hline Male & $27(20.77 \%)$ & $33(25.39 \%)$ & 60 \\
\hline Female & $103(79.23 \%)$ & $97(74.61 \%)$ & 200 \\
\hline Total & 130 & 130 & 260 \\
\hline
\end{tabular}

Table 3: VAS \& Anti-inflammatory (injection Ketorolac) stats $(n=130)$

\begin{tabular}{|c|c|c|c|c|}
\hline & Group & Mean & $\begin{array}{c}\text { Std. } \\
\text { Deviation }\end{array}$ & $\begin{array}{l}\text { Std. Error } \\
\text { Mean }\end{array}$ \\
\hline \multirow{2}{*}{$\begin{array}{l}\text { VAS at } 2 \text { hours } \\
\text { Postoperatively }\end{array}$} & $\begin{array}{c}\text { Group } \\
\text { A }\end{array}$ & 1.6 & 1.6 & 0.14 \\
\hline & $\begin{array}{c}\text { Group } \\
\text { B }\end{array}$ & 2.9 & 2.1 & 0.18 \\
\hline \multirow{2}{*}{$\begin{array}{l}\text { VAS at } 6 \mathrm{hrs} \\
\text { Postoperatively }\end{array}$} & $\begin{array}{c}\text { Group } \\
\text { A }\end{array}$ & 1.7 & 1.7 & 0.15 \\
\hline & $\begin{array}{c}\text { Group } \\
\text { B }\end{array}$ & 3.1 & 1.8 & 0.16 \\
\hline \multirow{2}{*}{$\begin{array}{l}\text { VAS at } 12 \text { hours } \\
\text { Postoperatively }\end{array}$} & $\begin{array}{c}\text { Group } \\
\text { A }\end{array}$ & 1.6 & 1.8 & 0.16 \\
\hline & $\begin{array}{c}\text { Group } \\
\text { B }\end{array}$ & 2.6 & 1.9 & 0.16 \\
\hline \multirow{2}{*}{$\begin{array}{c}\text { No of anti- } \\
\text { inflammatory inj. } \\
\text { given in first } 12 \\
\text { hours }\end{array}$} & $\begin{array}{c}\text { Group } \\
\text { A }\end{array}$ & 1.0 & 0.7 & 0.06 \\
\hline & $\begin{array}{c}\text { Group } \\
\text { B }\end{array}$ & 1.3 & 0.8 & 0.07 \\
\hline
\end{tabular}

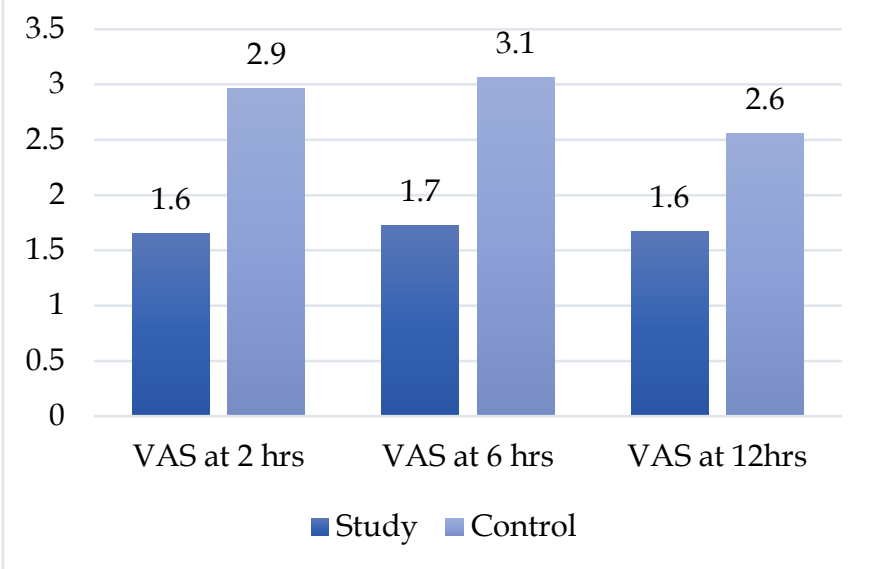

Figure 3: Mean VAS

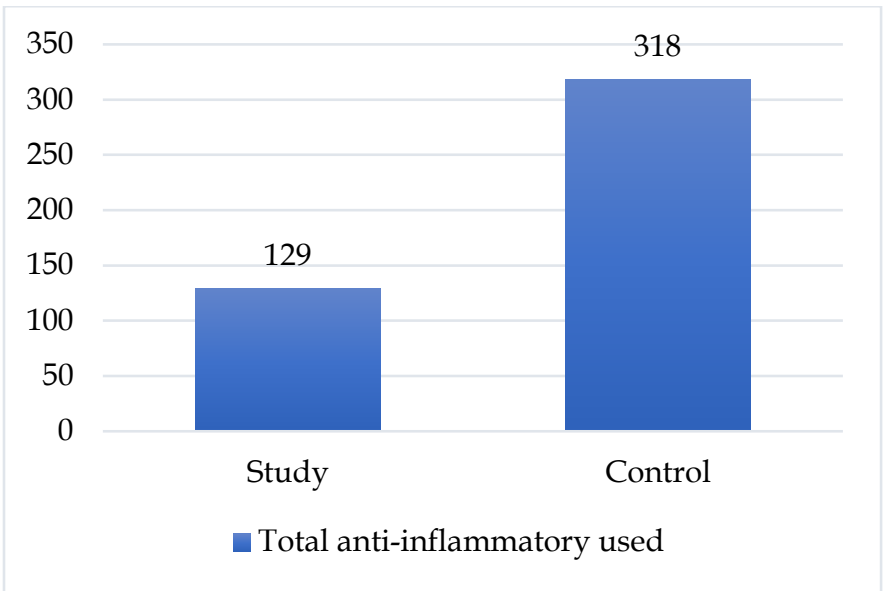

Figure 4: Total number of anti-inflammatory drugs used in both groups

\section{DISCUSSION}

Post-operative pain is a major problem of surgical practice and planning for its control should be born in 
mind of the surgeon preoperatively. In this regard, counseling of the patient about the degree of postoperative pain and different methods of its management is the most important. It helps in reducing the anxiety of the patient when they are explained about possible potoperative problems. ${ }^{7}$ Clinically, the importance of reduction of post-operative pain and nausea has become significant ever since the laparoscopic procedures especially, laparoscopic cholecystectomy has been considered as day case procedure. Early post-operative pain after laparoscopy is quite complex with different components, and is incisional, visceral, and shoulder tip pain. In early post-operative phase, the most important of all these three types of pain is incisional one because according to the reports, it is more intense than visceral pain. ${ }^{8}$

There have been many trials to evaluate the efficacy of subcutaneous infiltration of local anesthetic agents at incision sites in laparoscopic procedures. Report from the work of Liu et $a l^{3}$ showed that use of ropivacaine infiltrated at post sites in in patients undergoing laparoscopic cholecystectomy clearly reduces the magnitude of early post-operative pain. While Papagiananopoulou et $a l^{9}$ conducted a randomized double-blind study and their conclusion was that levobupivacaine is better in reducing the early postoperative pain compared with ropivacaine, when both infiltrated locally at post site. In our study we infiltrated bupivacaine locally at port sites, post-operatively and found that it significantly reduced the post-operative pain and hence the need of anti-inflammatory injectable in patients undergoing laparoscopic procedures.

There are some other studies concluding the clear advantages of the use of local anesthetic agents at port sites in laparoscopic procedure by reducing the early post-operative pain. Although considered to be associated with less pain due to being minimally invasive, in laparoscopic procedures, the pain originating from the skin is still a problem and prospective data shows favorable results for the use of local anesthetic agent at port sites.10,11 The result of the study from the work of M. Upadya, S.H. Pushpavathi and Kaushik Rao Seetharam showed that intraincisional infiltration of $20 \mathrm{ml}$ of $0.5 \%$ bupivacaine results in lower VAS and VRS in early post-operative phase. ${ }^{7} \mathrm{~A}$ thorough literature review has many evidences to show that the intra-incisional use of local anesthetic at post sites for pain relief is very effective and is quite long lasting. ${ }^{12}$

Bupivacaine is a good choice as local anesthetics in these laparoscopic cases because of its easy administration and being cheaper with an acceptable toxic effect profile but duration of its analgesia is questionable. The safety range of dose is up to $150 \mathrm{mg}$ as reported in many trials and pain reduction is there from 1 to 8 hours post-operatively and in studies where the dose used was less i.e., $90 \mathrm{mg}$, the analgesic effects were for half an hour post-operatively which shows that the duration may be dose dependent.5,13,14 In our study, the dose used was 100mg. In our study, we infiltrated the bupivacaine subcutaneously, post-operatively. The anatomical layer of infiltration of local anesthetic agent and timing of injection has been evaluated by many studies and is thought to be significant. Reports from the study $10^{19}$ show that local anesthetic was more effective when instilled in all the layers of anterior abdominal wall and work of Yangaard and colleagues showed that if the lidocaine is applied subfascially, it is more effective, compared to when it is applied subcutaneously in laparoscopic inguinal hernia repairs while some other studies show that infiltration of parietal peritoneum which is most pain sensitive results in best outcomes in patients undergoing appendectomy and cholecystectomies, laparoscopically, as far as reduction in severity of pain is concerned. ${ }^{15}$ This was lacking in our study.

In our study, we used Injection Ketorolac 30mg I/V (an NSAID), post-operatively for pain relief as per need of the patients in both groups and found that the need for antiinflammatory drug is greatly reduced if the port sites are infiltrated with injection bupivacaine. A study reviewing different choices for pain relief after laparoscopic cholecystectomy concludes that a combination of local anesthetic agent and an NSAID is quite effective modality and a choice for pain relief. ${ }^{16}$ While a study by Ziauddin A. Kashmiri ${ }^{17}$ and coworkers states that NSAIDs used for pain relief post-operatively in patients after laparoscopic cholecystectomy are not always fully effective rather because pneumoperitoneum results in the pathophysiological changes of renal blood flow, the use of NSAIDs can even be dangerous. Work of Jhonson et al 18 shows that when local anesthetic agent is used for pain relief, the use of anti-inflammatory agent has not got much role in reducing the post-operative pain and Hernadez-Palazon et al ${ }^{19}$ concluded that in patients with laparoscopic cholecystectomy, if bupivacaine is used for local pain relief, intra-peritoneally, it significantly reduces the need for pain killers in the first six hours, post-operatively.

The timing of local anesthetic agent infiltration whether given pre or post-operatively is not that much significant as shown by Sarac et al ${ }^{20}$ concluded that pre-operative injection is not effective compared to the one given postoperatively. Therefore, this is a debatable issue.

\section{CONCLUSION}

To make the laparoscopic surgery almost totally pain free, infiltration of local anesthetic agent at port site is a very good, easy and advantageous technique. It proves to be harmless as well and is associated with early return to routine daily activities in patients. Bupivacaine is the best available choice at the moment. The timing of injection 
and exact anatomical plain to be injected needs to be evaluated more.

\section{LIMITATIONS}

Non availability of injection bupivacaine

\section{SUGGESTIONS / RECOMMENDATIONS}

We recommend use of injection bupivacaine at port site in laparoscopic procedures.

\section{CONFLICT OF INTEREST / DISCLOSURE}

None.

\section{ACKNOWLEDGEMENTS}

We are thankful to our colleagues for their guidelines and support.

\section{REFERENCES}

1. Glötzl F, Aigner E. Orthodox Core-Heterodox periphery? Contrasting citation networks of economics departments in Vienna. Rev Political Econ 2018;30(2):210-40.

2. HerniaSurge Group. International guidelines for groin hernia management. Hernia. 2018;22(1):1-165.

3. Liu YY, Yeh CN, Lee HL, Wang SY, Tsai CY, Lin CC, et al. Local anesthesia with ropivacaine for patients undergoing laparoscopic cholecystectomy. World J Gastroenterol. 2009;15(19):2376-80.

4. Lin J, Iannettoni MD. Fast-tracking: eliminating roadblocks to successful early discharge. Thorac Surg Clin. 2005;15(2):221-8.

5. Gough AE, Chang S, Reddy S, Ferrigno L, Zerey M, Grotts J, Yim S, Thoman DS. Periprosthetic Anesthetic for Postoperative Pain After Laparoscopic Ventral Hernia Repair: A Randomized Clinical Trial. JAMA Surg. 2015;150(9):835-40.

6. Kato J, Ogawa S, Katz J, Nagai H, Kashiwazaki M, Saeki H, et al. Effects of presurgical local infiltration of bupivacaine in the surgical field on postsurgical wound pain in laparoscopic gynecologic examinations: a possible preemptive analgesic effect. Clin J Pain. 2000;16(1):12-7.

7. Upadya M, Pushpavathi SH, Seetharam KR. Comparison of intraperitoneal bupivacaine and intravenous paracetamol for postoperative pain relief after laparoscopic cholecystectomy. Anesth Essays Res. 2015;9(1):39-43.
8. Shengping Lin, Jie Hua, Bin $\mathrm{Xu}$, Ting Song Yang, Zhigang He, Chenglei $\mathrm{Xu}$, et al. Comparison of bupivacaine and parecoxib for postoperative pain relief after laparoscopic cholecystectomy: a randomized controlled trial. Int J ClinExp Med. 2015;8(8):13824-9.

9. Papagiannopoulou P, Argiriadou H, Georgiou M, Papaziogas B, Sfyra E, Kanakoudis F. Preincisional local infiltration of levobupivacaine vs ropivacaine for pain control after laparoscopic cholecystectomy. Surg Endosc. 2003;17(12):1961-4.

10. Alexnder DJ, Ngoi SS, Lee L, So J, Mak K, Chan S, et al. Randomized trial of periportal peritoneal bupivacaine for pain relief after laparoscopic cholecystectomy. Br J Surg. 1996;83;1223-5.

11. Dahl JB, Moiniche S, Kehlet H. Wound infiltration with local anaesthesia for postoperative pain relief. Acta Anaesthesiol Scand 1994;38(1):7-14.

12. Kehlet H, Gray AW, Bonnet F, Camu F, Fischer HB, McCloy RF, et al. A procedure-specific systematic review and consensus recommendations for postoperative analgesia following laparoscopic cholecystectomy. Surg Endosc. 2005;19(10):1396-415.

13. Gupta A. Local anaesthesia for pain relief after laparoscopic cholecystectomy--a systematic review. Best Pract Res Clin Anaesthesiol. 2005;19(2):275-92.

14. Chou YJ, Ou YC, Lan KC, Jawan B, Chang SY, Kung FT. Preemptive analgesia installation during gynecologic laparoscopy: a randomized trial. J Minim Invasive Gynecol. 2005;12(4):330-5.

15. Colbert S, O'Hanlon DM, Courtney DF, Quill DS, Flynn N. Analgesia following appendectomy- the value of peritoneal bupivacaine. Can J Anaesth. 1998;45(8):729-34.

16. Mitra S, Khandelwal P, Roberts K, Kumar S, Vadivelu N. Pain relief in laparoscopic cholecystectomy--a review of the current options. Pain Pract. 2012;12(6):485-96.

17. Ziauddin A. Kashmiri, Umair-ul-Islam, ShamsunnisaRashidi, Murtaza Ahsan Ansari. Post laparoscopic cholecystectomy pain relief. A comparison between Inj. Ketorolac along with infiltration of Inj. Bupivacaine at operation site \& Inj. Ketorlac along with intraperitoneal infiltration of Inj. Bupivacaine. Pak J Surg. 2013;29(2):110-14.

18. Johnson RC, Hedges AR, Morris R, Stamatakis JD. Ideal pain relief following laparoscopic cholecystectomy. Int J ClinPract. 1999;53(1):16-8.

19. Hernandez-Palazon J, Tortosa JA, Nuno de la Rosa V, GimenezViudes J, Ramirez G, Robles R. intraperitoneal application of Bupivacaine plus morphine for pain relief after laparoscopic cholecystectomy. Eur J Anaesthesiol. 2003;20(11):891-6.

20. Sarac AM, Aktan AO, Baykan N, Yegen C, Yalin R. The effect and timing of local anesthesia in laparoscopic cholecystectomy. Surg Laparosc Endosc. 1996;6(5):362-6. 